\title{
Size-resolved aerosol water-soluble ionic compositions in the summer of Beijing: implication of regional secondary formation
}

\author{
S. Guo ${ }^{1}$, M. Hu${ }^{1}$, Z. B. Wang ${ }^{1}$, J. Slanina ${ }^{1}$, and Y. L. Zhao ${ }^{2}$ \\ ${ }^{1}$ State Key Joint Laboratory of Environmental Simulation and Pollution Control, College of Environmental Sciences and \\ Engineering, Peking University, Beijing 100871, China \\ ${ }^{2}$ Department of Environmental Science, Policy and Management, University of California, Berkeley, CA 94720, USA
}

Received: 29 July 2009 - Published in Atmos. Chem. Phys. Discuss.: 11 November 2009

Revised: 20 January 2010 - Accepted: 20 January 2010 - Published: 1 February 2010

\begin{abstract}
To characterize aerosol pollution in Beijing, size-resolved aerosols were collected by MOUDIs during CAREBEIJING-2006 field campaign at Peking University (urban site) and Yufa (upwind rural site). Fine particle concentrations $\left(\mathrm{PM}_{1.8}\right.$ by MOUDI) were $99.8 \pm 77.4 \mu \mathrm{g} / \mathrm{m}^{3}$ and $78.2 \pm 58.4 \mu \mathrm{g} / \mathrm{m}^{3}$, with $\mathrm{PM}_{1.8} / \mathrm{PM}_{10}$ ratios of $0.64 \pm 0.08$ and $0.76 \pm 0.08$ at PKU and Yufa, respectively, and secondary compounds accounted for more than $50 \%$ in fine particles. PMF model analysis was used to resolve the particle modes. Three modes were resolved at Yufa, representing condensation, droplet and coarse mode. However, one more droplet mode with bigger size was resolved, which was considered probably from regional transport. Condensation mode accounted for $10 \%-60 \%$ of the total mass at both sites, indicating that the gas-to-particle condensation process was important in summer. The formation of sulfate was mainly attributed to in-cloud or aerosol droplet process (PKU 80\%, Yufa 70\%) and gas condensation process (PKU $14 \%$, Yufa 22\%). According to the thermodynamic instability of $\mathrm{NH}_{4} \mathrm{NO}_{3}$, size distributions of nitrate were classified as three categories by $\mathrm{RH}$. The existence of $\mathrm{Ca}\left(\mathrm{NO}_{3}\right)_{2}$ in droplet mode indicated the reaction of $\mathrm{HNO}_{3}$ with crustal particles was also important in fine particles. A rough estimation was given that $69 \%$ of the $\mathrm{PM}_{10}$ and $87 \%$ of the $\mathrm{PM}_{1.8}$ in Beijing urban were regional contributions. Sulfate, ammonium and oxalate were formed regionally, with the regional contributions of $90 \%, 87 \%$ and $95 \%$ to $\mathrm{PM}_{1.8}$. Nitrate formation was local dominant. In summary regional secondary formation led to aerosol pollution in the summer of Beijing.
\end{abstract}

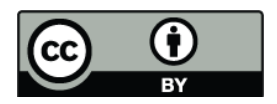

Correspondence to: $\mathrm{M} . \mathrm{Hu}$ (minhu@pku.edu.cn)

\section{Introduction}

Beijing is the capital and a major metropolis of China with the resident population of over 16 million (NBSC, 2009a). With the rapid economic development, large energy consumption (4.7 million tons of coal in 2008, NBSC, 2009b) and increase of vehicles (10-15\% per year, NBSC, 2009b), Beijing has led to air pollution problems. Additionally, Beijing's dustpan shaped topography does not favor air pollution diffusion. Great efforts have been made by Beijing EPB (Beijing Environmental Protection Bureau) to control primary emission. As a result, $\mathrm{SO}_{2}$ and $\mathrm{NO}_{2}$ have met China National Air Quality Standards. However, particles and $\mathrm{O}_{3}$ have become the major air pollutants, and the presence of regional and secondary pollution in cities has been recognized recently. It is a serious environmental challenge for China to solve these problems (Shao et al., 2006).

Many studies on chemical compositions of $\mathrm{PM}_{10}$ and $\mathrm{PM}_{2.5}$ in Beijing have been reported since last few years (He et al., 2001; Yao et al., 2002; Yang et al., 2005; Sun et al., 2006). However, the integrated particle compositions can not well characterize the secondary formation process. Size distributions of aerosol water-soluble ionic compositions can help to understand aerosol transformation, transport, and fate, but only a few studies focused on particle size distributions in Beijing (Yao et al., 2003; Hu et al., 2005a; van Pinxteren, 2009). Moreover, most of previous studies in Beijing were single-site measurements and concentrated on the urban area of Beijing. Model studies on characterizing regional particle pollution of Beijing area are available (Wang et al., 2008), but very few experimental validations were given (Han et al., 2005). It is even rare to quantify the regional component of urban aerosol (Jia et al., 2008). Thus it is necessary to study the size distributions of the secondary

Published by Copernicus Publications on behalf of the European Geosciences Union. 
aerosols to understand their formation pathways in the regional scale in Beijing.

In this study size-resolved samples were collected by two Micro-Orifice Uniform Deposit Impactors (MOUDIs) at an urban site (Peking University, PKU) and an upwind rural site (Yufa) simultaneously. The size-resolved characteristics of particle mass and chemical compositions were investigated to explore possible formation pathways of secondary compounds and to estimate the regional particle contribution.

\section{Experiment}

\subsection{Filter measurement}

MOUDI-110 (10 stages, MSP Corporation, USA) and MOUDI-100 (8 stages, MSP Corporation, USA) were used to sample size-segregated aerosols at PKU and Yufa respectively during CAREBEIJING-2006 summer intensive field campaign. The sampling flow rate was $30 \mathrm{~L} / \mathrm{min}$, and the $50 \%$ cut points of MOUDI-100 were as follows: 10, 5.6, 3.2, $1.8,1.0,0.56,0.32$ and $0.18 \mu \mathrm{m}$. MOUDI-110 has two more fine stages with the cut points of 0.1 and $0.056 \mu \mathrm{m}$. PKU, the urban site $\left(39^{\circ} 59^{\prime} 21^{\prime \prime} \mathrm{N}, 116^{\circ} 18^{\prime} 25^{\prime \prime} \mathrm{E}\right)$, was on the roof of an academic building (about $15 \mathrm{~m}$ above the ground level) on the campus of Peking University in the northwestern of Beijing. There were no obvious emission sources nearby except two major roads, $150 \mathrm{~m}$ to the east and $200 \mathrm{~m}$ to the south. Yufa, the rural site $\left(39^{\circ} 30^{\prime} 49^{\prime \prime} \mathrm{N}, 116^{\circ} 18^{\prime} 15^{\prime \prime} \mathrm{E}\right)$, was about $53 \mathrm{~km}$ to the south of PKU, on top of a building (about $20 \mathrm{~m}$ above the ground level) at the campus of Huangpu College. Around the site was nothing but farm land and residential area.

Three-period MOUDI samples (morning, afternoon and night) were collected: morning (07:00-11:30, marked A), afternoon (12:00-18:00, marked P), night (18:30-06:30, marked $\mathrm{N}$ ). The afternoon sampling periods matched the diurnal $\mathrm{O}_{3}$ peak. In some days, daytime was not divided to ensure that the mass was enough for analysis (marked AP). Teflon filters (Whatman Inc. Clifton, NJ, USA) were used. Before and after sampling, the filters were weighed in Peking University's clean room after $24 \mathrm{~h}$ conditioning under constant temperature $\left(20 \pm 1{ }^{\circ} \mathrm{C}\right)$ and $\mathrm{RH}(40 \pm 3 \%)$. The filter preparation and sampling method were the same as $\mathrm{Hu}$ et al. (2005a).

Totally 28 and 45 sets of samples were collected at PKU and Yufa, respectively. After sampling, the filters were put back in their own Petri dishes, and stored in a refrigerator at the temperature of $-20^{\circ} \mathrm{C}$. During transport to the laboratory they were kept in ice boxes.

The samples were extracted by $10 \mathrm{ml}$ de-ionized water using an ultrasonic bath for $30 \mathrm{~min}$ at room temperature, and then the extracted liquid was analyzed by ion-chromatograph (DIONEX, ICS-2500). The IC analysis methods were the same as Hu et al. (2005b). An AS11 column (4 mm) with an AG11-HC $(4 \times 50 \mathrm{~mm})$ guard column and an Anion Trap column (ATC-3, $9 \times 24 \mathrm{~mm}$, for $4 \mathrm{~mm}$ ) were used for anion detection with an eluent of $0.4-6 \mathrm{mM} / \mathrm{L} \mathrm{NaOH}(1.2 \mathrm{~mL} / \mathrm{min}$, gradient). Cations were analyzed by CS-12A Column, with a CG-12A $(4 \times 50 \mathrm{~mm})$ guard column, CSRS-I suppressor. The eluent was $20 \mathrm{mM} / \mathrm{L}$ MSA with a flow rate of $1.0 \mathrm{~mL} / \mathrm{min}$.

Totally five kinds of cations $\left(\mathrm{Na}^{+}, \mathrm{NH}_{4}^{+}, \mathrm{K}^{+}, \mathrm{Mg}^{2+}\right.$ and $\left.\mathrm{Ca}^{2+}\right)$, four kinds of anions $\left(\mathrm{F}^{-}, \mathrm{Cl}^{-}, \mathrm{NO}_{3}^{-}\right.$and $\left.\mathrm{SO}_{4}^{2-}\right)$, and three kinds of low molecular weight water soluble organic compounds (formate, acetate and oxalate) were analyzed with the detection limits of $0.03,0.06,0.1,0.1,0.05$, $0.03,0.03,0.01,0.01,0.06,0.06$ and $0.02 \mathrm{mg} / \mathrm{L}$ in liquid. Field and laboratory blanks were analyzed using the same method, and the blank concentrations were all below the detection limits. For inter-comparison of two MOUDIs, please see supplement material http://www.atmos-chem-phys.net/ 10/947/2010/acp-10-947-2010-supplement.pdf.

\subsection{Online instrument}

Online instrument Wet Denuder-SJAC (Steam Jet Aerosol Collector) system (Slanina, et al., 2001) was also used in this study to measure particle compositions $\mathrm{SO}_{4}^{2-}, \mathrm{NO}_{3}^{-}, \mathrm{NH}_{4}^{+}$ and gaseous $\mathrm{NH}_{3}$ and $\mathrm{HNO}_{3}$. A wet denuder system was used to scavenge interfering gaseous nitrogen compounds, in this case ammonia and nitric and nitrous acid. The absorption solution is a $10^{-5} \mathrm{M}$ carbonate solution which effectively retains all gaseous interferences. Then particles can go through the wet denuder and are captured by steam which was generated by SJAC. The solution is finally analyzed by ion chromatogram. The sampling flow rate was $16.7 \mathrm{~L} / \mathrm{min}$ and the time resolution was $30 \mathrm{~min}$.

\section{Results and discussion}

\section{1 $\mathrm{PM}_{10}$ concentrations and definitions of "polluted" and "clean" episodes}

MOUDI does not have a $2.5 \mu \mathrm{m}$ cut point, so the diameter of $1.8 \mu \mathrm{m}$ is defined as the cut point that splits fine and coarse particles in this study. Therefore, $\mathrm{PM}_{1.8}$ and $\mathrm{PM}_{1.8-10}$ presented fine and coarse particles, respectively. $24 \mathrm{~h}$ average $\mathrm{PM}_{10}$ concentrations were $171.5 \pm 91.4 \mu \mathrm{g} / \mathrm{m}^{3}$ at PKU and $111.6 \pm 73.2 \mu \mathrm{g} / \mathrm{m}^{3}$ at Yufa, respectively (Table 1). In average, both fine and coarse particle concentrations at PKU were higher than those at Yufa. These years $\mathrm{PM}_{1.8}, \mathrm{PM}_{10}$ and $\mathrm{PM}_{1.8} / \mathrm{PM}_{10}$ all increased, compared with the results in summer of 2001, 2002 and 2006, indicating the fine particles have become the major component of $\mathrm{PM}_{10}$, and determined the fluctuation of $\mathrm{PM}_{10}$. In the year 2002 and 2006, secondary compounds $\left(\mathrm{SO}_{4}^{2-}+\mathrm{NO}_{3}^{-}+\mathrm{NH}_{4}^{+}\right)$composed more than half of the fine particle mass, suggesting secondary particle pollution was more and more important these years. 
Table 1. Comparison of $\mathrm{PM}_{10}, \mathrm{PM}_{1.8}$, ratios of $\mathrm{PM}_{1.8} / \mathrm{PM}_{10}$ and $\mathrm{SNA} / \mathrm{PM}_{1.8}$ with other study ( $\mu \mathrm{g} / \mathrm{m}^{3}$ ). SNA: mass sum of $\left(\mathrm{SO}_{4}^{2-}+\mathrm{NO}_{3}^{-}+\mathrm{NH}_{4}^{+}\right.$.

\begin{tabular}{lllllll}
\hline Site & $\mathrm{PM}_{10}$ & $\mathrm{PM}_{1.8}$ & $\mathrm{PM}_{1.8} / \mathrm{PM}_{10}$ & $\mathrm{SNA} \mathrm{PM}_{1.8}$ & Year-month & Reference \\
\hline PKU & $171.5 \pm 91.4$ & $99.8 \pm 74.4$ & $0.64 \pm 0.08$ & $0.53 \pm 0.19$ & Aug 2006 & This study \\
Yufa & $111.6 \pm 73.2$ & $78.2 \pm 58.4$ & $0.76 \pm 0.08$ & $0.58 \pm 0.18$ & Aug 2006 & This study \\
PKU & $113.0 \pm 55.8$ & $52.0 \pm 35.3$ & $0.44 \pm 0.13$ & $0.35 \pm 0.17$ & Jul 2001 & Hu, 2005a \\
PKU & $130.9 \pm 87.2$ & $70.4 \pm 56.5$ & $0.51 \pm 0.12$ & $0.55 \pm 0.19$ & Jul 2002 & Hu, 2005a \\
\hline
\end{tabular}
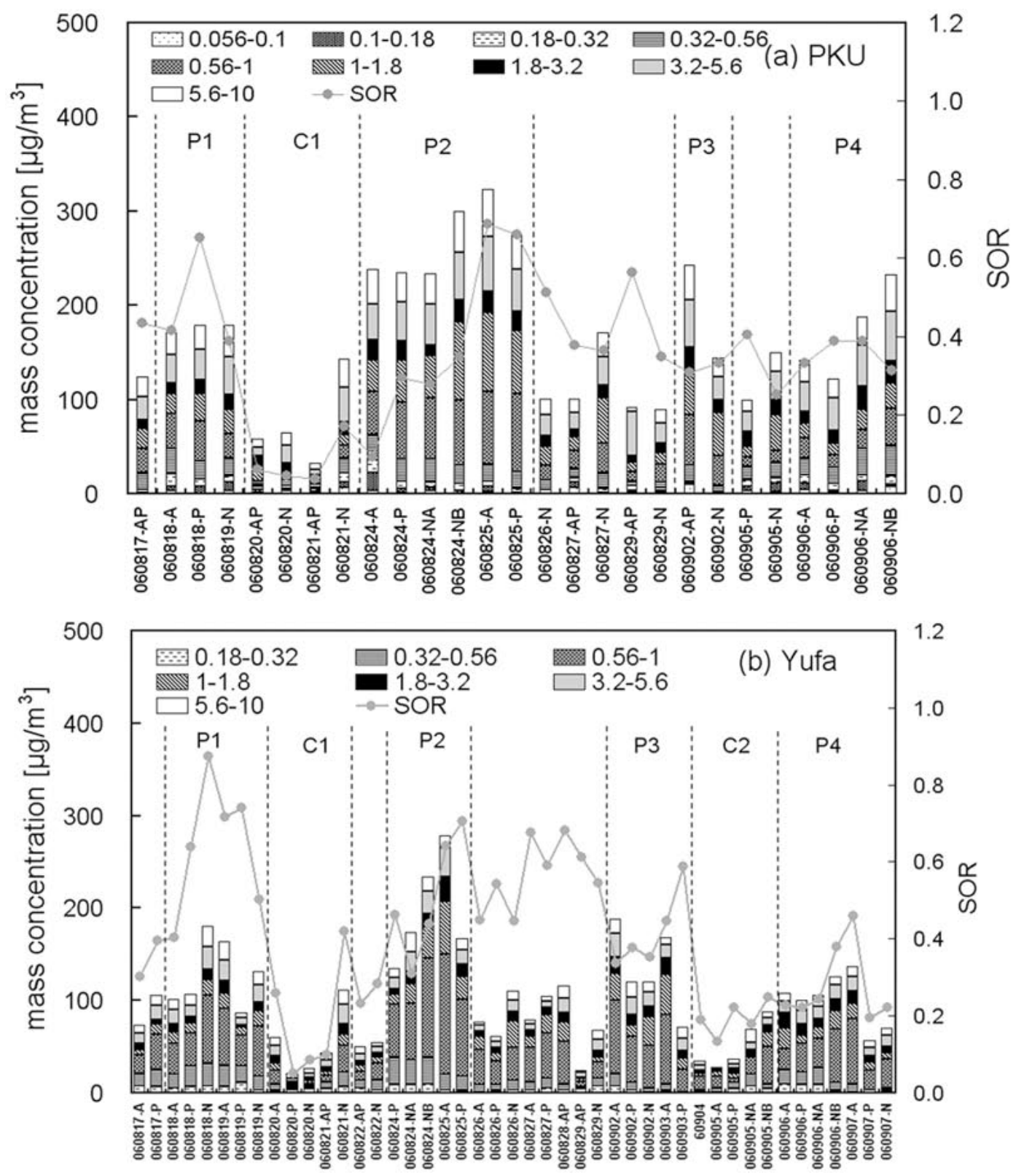

Fig. 1. $\mathrm{PM}_{10}$ and size-segregated particle mass concentrations for each sample during the campaign. (a) PKU, (b) Yufa. The samples are given the ID as yymmdd-X, where $\mathrm{X}$ denotes sampling core time of morning $(\mathrm{A})$, afternoon $(\mathrm{P})$ and night $(\mathrm{N})$. 
Figure 1 showed the size resolved $\mathrm{PM}_{10}$ concentrations and SORs (molar ratio of the particulate sulfate to the total sulfur $\mathrm{SO}_{4}^{2-}+\mathrm{SO}_{2}$ ) at two sites. Particles in stages of $0.56-1 \mu \mathrm{m}$ and $1-1.8 \mu \mathrm{m}$ consisted large fraction of total particles. $\mathrm{PM}_{10}$ as well as SORs exhibited similar trend at both sites with obvious cycles of pollution increase and decrease. "Polluted" and "clean" episodes are defined based on particle mass concentrations, SORs and meteorological conditions. Totally four "polluted episodes" are defined as the days with high $\mathrm{PM}_{10}$ concentrations ( $\left.>100 \mu \mathrm{g} / \mathrm{m}^{3}\right)$, stagnant meteorological conditions (wind speed $<1 \mathrm{~m} / \mathrm{s}$ ), high temperature $\left(>30^{\circ} \mathrm{C}\right)$ and $\mathrm{RH}(>70 \%)$, that is, 18th to 19th August, 24th to 25th August, 2nd to 3rd September and 6th to 7th September (Fig. 1: P1-P4). The SORs during the polluted episodes were higher than 0.3. Two "clean episodes" were observed during 20th to 21st August and 4th to 5th September (Fig. 1: C1-C2, samples were not collected on 4th September at PKU for technical reason, so $\mathrm{C} 2$ is only for Yufa site), with strong wind (max wind speed $>4 \mathrm{~m} / \mathrm{s}$ ), high temperature $\left(>30^{\circ} \mathrm{C}\right.$ ) but low RH $(<50 \%)$. The SORs during the clean episodes were lower than 0.2 .

NOAA's HYSPLIT4 trajectory model (www.arl.noaa.gov/ hysplit.html) was used to calculate 24-h backward trajectories for different episodes (Fig. 2). The backward trajectories of polluted episodes came from the surrounding area of Beijing (mainly from south), and the paths were short because of low wind speed. The backward trajectories of clean episodes originated mostly from far north of Beijing, where the air is relatively clean. The strong wind took the clean air to scavenge and dilute the polluted air in Beijing. For general description of gaseous pollutants and meteorological conditions during two types of episodes, please see supplement material http://www.atmos-chem-phys.net/10/947/ 2010/acp-10-947-2010-supplement.pdf.

All in all, in the summer of Beijing fine particles were dominant in $\mathrm{PM}_{10}$. The stagnant atmosphere favored secondary transformation and pollution accumulation. The precipitation or strong wind from north interrupted the pollution accumulation process. Thus the "polluted" and "clean" episodes occurred alternately.

\subsection{Size distributions of mass and ionic compounds}

\subsubsection{Resolving size distribution modes}

Ambient aerosol distribution is characterized by a number of modes. Usually, aerosol mass is dominated by bimodal distribution, the accumulation mode and coarse mode. In some cases the accumulation mode consists of two overlapping sub-modes: the condensation mode and the droplet mode. Aerosol mode distribution reflects the origin of aerosol. For instance, the condensation sub-mode is the result of growth of ultrafine particles by coagulation and vapor condensation. The droplet sub-mode was formed by in-cloud process or aqueous reaction. Thus, it is helpful to distinguish the mode

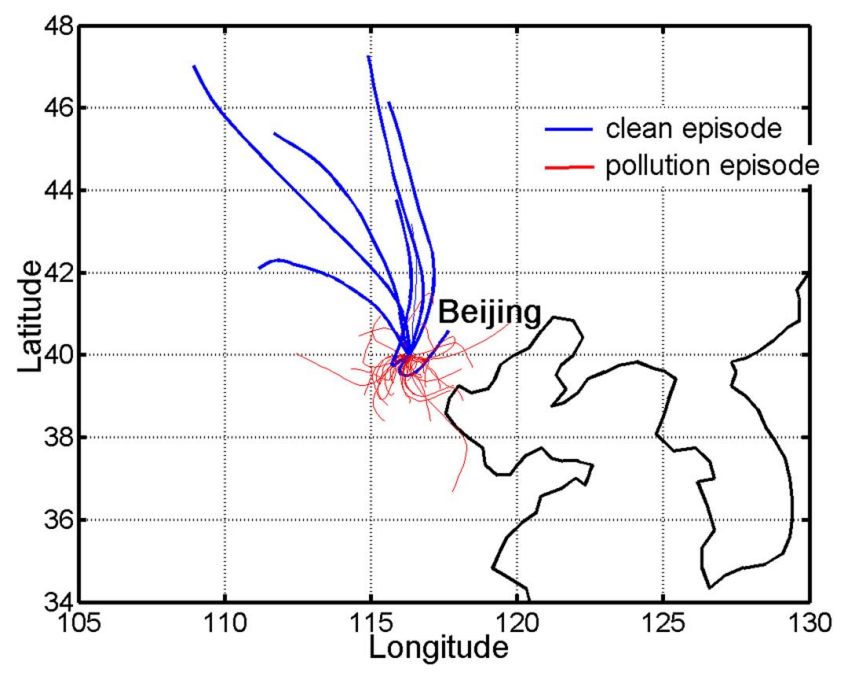

Fig. 2. 24-h backward trajectories during the campaign. Two backward trajectories per day with the starting time at 12:00 and 24:00 (local time), at the starting height of $100 \mathrm{~m}$.

distribution so as to track the formation path for secondary composition. Factor analysis techniques are good methods to resolve the overlapping peaks (Frenich et al., 2000), among which the positive matrix factorization (PMF) model has recently been successfully applied to the resolution of different particle modes (Kim et al., 2004; Huang et al, 2006). Totally 196 sets $(7$ species $\times 8$ samples) sets and 315 sets ( 7 species $\times 45$ samples of size distribution data were generated at PKU and Yufa, respectively, with 7 species of mass and 6 measured chemical compositions $\left(\mathrm{SO}_{4}^{2-}, \mathrm{NO}_{3}^{-}\right.$, oxalate, $\mathrm{NH}_{4}^{+}$, $\mathrm{Ca}^{2+}$ and $\mathrm{K}^{+}$). PMF analysis was performed on these data at PKU and Yufa separately with the number of factors fixed at three or four according to the measured size distribution.

PMF is a multivariate factor analysis tool that decomposes a matrix of speciated sample data into two matrices (factor contributions and factor profiles). In the case of this study, MOUDI size distribution data can be viewed as a data matrix $\mathbf{X}$ of $i$ by $j$ dimensions, in which $i$ is the number of samples and $j$ is the number of particle size bins (MOUDI stages). PMF is to identify a number of factors $p$, the MOUDI stage profile $f$ of each source, and the amount of mass $g$ contributed by each factor to each individual sample (see Eq. 1):

$\mathbf{X}_{i j}=\sum_{k=1}^{p} g_{i k} f_{k j}+e_{i j}$

where $g_{i k}$ is the amount of mass contributed by each factor to each individual sample, $f_{k j}$ is the species profile of each source, $e_{i j}$ is the residual for each sample/species.

As a result, the concentration of each MOUDI stage was decomposed into three or four factors due to the different sources. In other words, each mass size distribution (total mass or mass of each chemical composition) of every single sample was decomposed into three or four distributions 
Table 2. PMF resolved average particle concentrations for each mode at two sites during the "polluted" episodes. A: morning, P: afternoon, $\mathrm{N}$ : night $\left(\mu \mathrm{g} / \mathrm{m}^{3}\right)$.

\begin{tabular}{llllllll}
\hline \multicolumn{3}{c}{ PMF-resolved Yufa average } & \multicolumn{5}{c}{ PMF-resolved PKU average } \\
\hline & Condensation & Droplet & Coarse & Condensation & Droplet-1 & Droplet-2 & Coarse \\
\hline Mass-A & 26.3 & 58.2 & 24.2 & 13.9 & 81.8 & 23.9 & 59.7 \\
Mass-P & 28.5 & 52.5 & 22.5 & 6.6 & 103.8 & 24.9 & 71.3 \\
Mass-N & 29.5 & 53.6 & 26.4 & 7.5 & 54.7 & 28.7 & 65.8 \\
$\mathrm{SO}_{4}^{2-}-\mathrm{A}$ & 6.3 & 21.6 & 3.1 & 3.4 & 14.2 & 9.8 & 0.9 \\
$\mathrm{SO}_{4}^{2-}-\mathrm{P}$ & 9.1 & 26.4 & 1.8 & 5.6 & 17.5 & 10.4 & 2.5 \\
$\mathrm{SO}_{4}^{2-}-\mathrm{N}$ & 4.4 & 19.1 & 1.9 & 4.3 & 11.0 & 9.5 & 2.6 \\
$\mathrm{NO}_{3}^{-}-\mathrm{A}$ & 1.9 & 7.0 & 3.2 & 0.5 & 1.9 & 9.9 & 10.5 \\
$\mathrm{NO}_{3}^{-}-\mathrm{P}$ & 0.3 & 2.4 & 5.0 & 0.7 & 2.5 & 8.7 & 11.0 \\
$\mathrm{NO}_{3}^{-}-\mathrm{N}$ & 2.4 & 9.2 & 2.7 & 0.3 & 5.9 & 7.4 & 5.4 \\
\hline
\end{tabular}

(factors). Average size distributions for each factor were calculated by averaging all the same stages in one factor (e.g. The resolved concentrations in all $0.56-1 \mu \mathrm{m}$ stages of factor 1 are averaged to get the average concentration of $0.56-$ $1 \mu \mathrm{m}$ for factor 1$)$. The sum concentration of all stages in one factor is the contribution of this factor to total mass concentration, and lognormal fit was used to get each factor's mass medium aerodynamic diameter (MMAD). The factors are named after well known particles submodes (condensation mode, droplet mode and coarse mode) according to their MMADs.

The measured and resolved average size distributions were shown in Fig. 3. For rural Yufa site, apparent three modes were resolved by PMF with at $0.4,0.8$, and $5.7 \mu \mathrm{m}$, corresponding to the condensation mode, droplet mode, and coarse mode, respectively (Fig. 3). The results were similar to those of the rural aerosols in Shenzhen, China (Huang et al., 2006). However, four modes of particle mass were resolved at PKU, with the MMADs at $0.4,0.8,1.4$ and $5.7 \mu \mathrm{m}$, corresponding to the condensation mode, droplet mode-1, droplet mode- 2 , and coarse mode, respectively. One more droplet mode with bigger size was resolved at urban site. Three factors were chosen because two similar modes would be resolved if factor number was fixed at four. The reason is the same for PKU site. Moreover, numbers of factors were also decided according to the measured size distribution and scientific rationality.

\subsubsection{Size distributions at Yufa}

The measured mass size distribution showed bimodal size distributions with the peaks at the stages of $0.56-1 \mu \mathrm{m}$ and 3.2-5.6 $\mu \mathrm{m}$ at Yufa (Fig. 4 a-2), which was consistent with the previous study in Beijing (Yao et al., 2003). The PMF model resolved three modes of condensation mode, droplet mode and coarse mode. The PMF model separated the condensation and droplet mode based on MOUDI measured re- sults, and the condensation mode accounted for $10 \%-60 \%$ of the total mass, indicating the condensation mode, which was neglected by previous study, was also important in summer of Beijing, and should be taken into account.

During the polluted episodes droplet mode was the dominant mode, and the percentage of this mode in total mass did not vary a lot, with $54 \%, 51 \%$ and $49 \%$ in the morning, afternoon and night, respectively (Table 2). Correspondingly, the condensation mode accounted for $24 \%, 27 \%$ and $27 \%$ of the total mass, respectively. In contrast during the clean episodes under the dry and cool weather condition, the droplet mode particles did not favor to form due to lack of water vapor in the atmosphere. Thus, the droplet mode was no longer the major mode instead of the coarse mode and the condensation mode with the average fractions of $47 \%$ and $42 \%$ in the total mass, respectively.

The measured sulfate, nitrate and ammonium all showed bimodal size distribution with two peaks at $0.56-1 \mu \mathrm{m}$ and 3.2-5.6 $\mu \mathrm{m}$ (Fig. 4), and they were all resolved into three modes by PMF model. However, these compounds had different diurnal variations and bimodal shapes. Sulfate had a major fine mode peak and a small coarse mode peak. The highest concentration occurred in the afternoon, because of the strong production process. The PMF model results exhibited the same diurnal variation, but resolved tri-modal distribution, a predominant droplet mode, a small condensation mode, and a small coarse mode. The PMF results also showed that although the concentration of sulfate varied with time, the percentage of each mode did not change much, which means the distribution did not change with time. However, nitrate showed a different diurnal variation from sulfate, with highest concentration at night and lowest in the afternoon, and it had a larger coarse mode with the fractions of $26 \%, 63 \%$ and $19 \%$ in the morning, afternoon and night respectively. Moreover, the nitrate distribution varied with time. In the morning and night samples, droplet mode was 

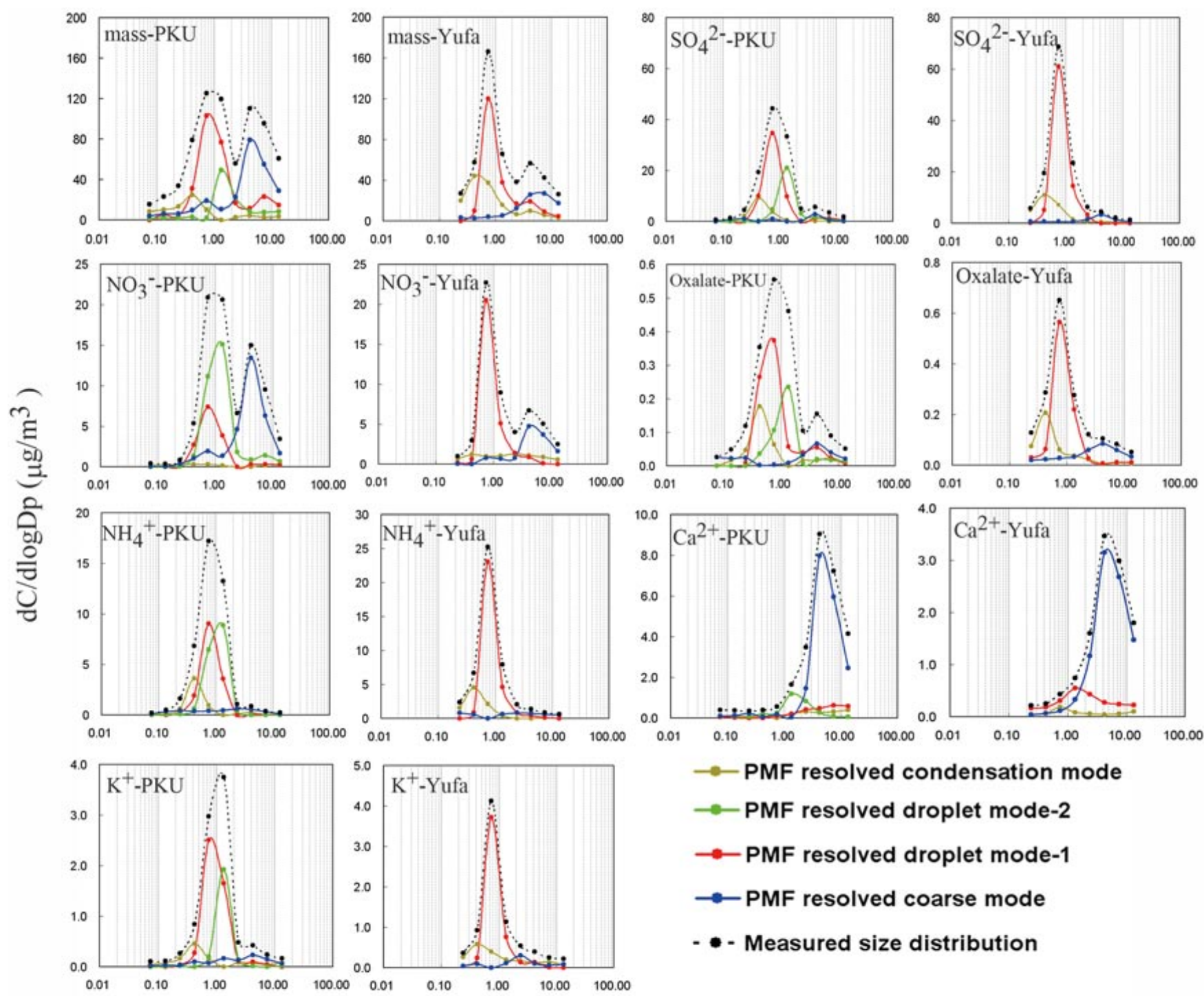

$\rightarrow-$ PMF resolved condensation mode

$\rightarrow$ PMF resolved droplet mode-2

$\rightarrow-$ PMF resolved droplet mode-1

$\rightarrow-$ PMF resolved coarse mode

- - Measured size distribution

Particle aerodynamic diameter $(\mu \mathrm{m})$

Fig. 3. The average measured size distribution curves and the PMF resolved four-modal or three-modal curves for the mass and major ionic species.

the dominant mode accounting for $58 \%$ and $64 \%$ of the total nitrate, but in the afternoon coarse mode became the major mode. Ammonium had a similar bimodal shape to sulfate but showed no apparent day-night variation, and the highest ammonium concentration occurred in the morning.

Oxalate was the most abundant dicarboxylic acid, whose mass concentration accounted for $0.4 \%$ in $\mathrm{PM}_{10}$ and $0.5 \%$ in $\mathrm{PM}_{1.8}$. Its size distributions were similar to those of sulfate. Formate and acetate can be measured in most of the samples $\left(0.2 \%\right.$ and $0.2 \%$ in $\left.\mathrm{PM}_{1.8}\right)$, and they were found in both fine and coarse particles, with $55 \%$ and $58 \%$ in the fine mode, respectively.

\subsubsection{Size distributions at PKU}

At PKU the size distributions of mass and major ionic composition were similar to those at Yufa, but there were several differences. (1) Four modes were resolved by PMF, with one more droplet mode with bigger size. (2) The fine particle peak for morning and afternoon were the same as Yufa at $0.56-1 \mu \mathrm{m}$, while at night the peak "shifted" to bigger size of $1-1.8 \mu \mathrm{m}$, indicating the resolved droplet mode with bigger size was reasonable. (3) Coarse mode contributed more at PKU than that at Yufa. For road dust and construction work were major contributors to coarse mode particle in summer of Beijing (Song et al., 2006), more resuspended dust by traffic 
and more construction works before Olympics may be the reason why PKU site had a larger coarse mode.

The first two differences will be discussed together here. Some researches have also measured this peak "shift". Anlauf et al. (2006) considered the shifts of the fine mode peaks at night were due to some aqueous-phase production. The shifts may also be simply due to increased water content at the high values of relative humidity. Liu et al. (2008) also measured large amount of particles in the stage of $1-1.8 \mu \mathrm{m}$ at night, and they suggested these particles may be from the hygroscopic growth of particles of $0.56-1 \mu \mathrm{m}$. However, these cannot fully explain the bigger size droplet mode particles in this study, because the fine mode peaks did not "shift" to bigger size at Yufa, while the gaseous precursor's concentration, temperature and RH at both sites were all similar.

This study considered these bigger size droplet mode particles were produced and grew during regional transport, and the different upwind conditions of two sites led to the different size distributions. The upwind area of the PKU site was polluted urban area, and when the particles passed through the urban area, they were aged and grew to bigger size. Differently, the upwind area of Yufa was not so polluted (at least within tens of kilometers), and under this condition the particles did not favor to grow up. Evidence is the t-test results showed that during the stagnant south wind days, the bigger size droplet mode moderately correlated with wind speed, and the bigger size droplet mode at PKU correlated with the droplet mode at Yufa with correlation coefficient of 0.74. PMF results could provide more information to explain these particles. Two droplet modes were resolved by PMF, a similar droplet mode as that at Yufa and an extra droplet mode with bigger size. The mass concentrations of the bigger size droplet mode had no significant diurnal variation, and showed no correlation with $\mathrm{O}_{3}$, indicating the source of these particles was persistent and was less related with $\mathrm{O}_{3}$ chemistry. A recent work by Chen et al. (2009) gave a support for this explanation. They suggested the mountainvalley breeze dominated the wind flow of the Beijing region during summer. Air pollutants were injected from the planetary boundary layer into the free troposphere due to the convection during daytime, and then were long distance transported from south to north. At the night time the particulate pollutants were transported back to the city again, when they were aged by in-cloud process and grow up.

Another source of this bigger size droplet mode may be from the reaction of gaseous $\mathrm{HNO}_{3}$ with small crustal particles. However, this was not an important source, and will be discussed in the following Sect. 3.2.2.

\subsection{Formation of sulfate, nitrate and oxalate}

\subsubsection{Formation of sulfate}

PMF-resolved particles of different modes were actually from different sources. For secondary compounds, the dif- ferent sources means different formation pathways, so PMF results can be used to estimate the contributions of different formation pathways. This estimation needs to meet two restrictive conditions: 1) the component must be mainly from secondary transformation; 2) The formation pathways of the component must be known.

Sulfate can come from both primary and secondary sources. Biomass burning such as wood burning and meat cooking can release particulate sulfate at the size range of about $0.1 \mu \mathrm{m}$. Water-soluble $\mathrm{K}^{+}$is a good tracer for biomass burning, and the ratios of mass concentrations of $\mathrm{K}^{+}$to sulfate are usually larger than one in the biomass burning particles (Kleeman et al., 1999). In this study, the ratios were $0.10 \pm 0.06$ and $0.11 \pm 0.10$ at PKU and Yufa, respectively. Moreover, both measured and model resolved mode concentrations of $\mathrm{K}^{+}$and sulfate showed poor correlations at the two sites. These results indicate that direct sulfate emission by biomass burning could be ignored. Vehicles also emit particulate sulfate, and the Cassiar tunnel measurements of particles indicated a mass ratio of $\mathrm{Na}^{+}$to $\mathrm{SO}_{4}^{2-}$ of about 0.05 (Anlauf et al., 2006). The average ratios for the 0.56 $1 \mu \mathrm{m}$ particles at PKU and Yufa were 0.018 and 0.017 , and the ratios would be less considering that sodium was also contributed by other sources. Generally, notwithstanding the large quantities of primary emission, fine mode sulfate mainly came from secondary sources.

Numerous studies have been carried on formation pathway of sulfate, and its formation mechanisms are relatively well understood. Several possible formation processes have been proposed to explain the droplet mode sulfate, including condensation and coagulation of smaller particles, in-cloud processes and the growth of the condensation mode by addition of sulfate and water (aerosol droplet process). The condensation mode sulfate arises from homogeneous gas phase photochemical oxidation of $\mathrm{SO}_{2}$ followed by gas-to-particle conversion (Seinfeld and Pandis, 1998). The coarse mode sulfate could be attributed to heterogeneous reactions of $\mathrm{SO}_{2}$ on soil particles (Zhuang et al., 1999). However, the contributions of these formation pathways alter with temporal and spatial variation. Although the previous study has concluded the sulfate was attributed to in-cloud processes in the summertime of Beijing (Yao, et al., 2003), the contributions of different formation pathways have not been quantified yet, because different particle modes cannot be quantificationally separated only by measured data. In this study, by using PMF model, different modes of sulfate were resolved from total sulfate, and the concentrations of resolved condensation mode, droplet mode and coarse mode can be regarded as the sulfates that were formed by gas-to-particle condensation process, in-cloud or aerosol droplet process and $\mathrm{SO}_{2}$ on soil particles heterogeneous reaction process, respectively.

As a result, in summer of Beijing, droplet mode was dominant, and an average fraction of $80 \%$ and $70 \%$ was attributed to in-cloud or aerosol droplet process at PKU and Yufa respectively. Correspondingly, $14 \%$ and $22 \%$ of the sulfate 

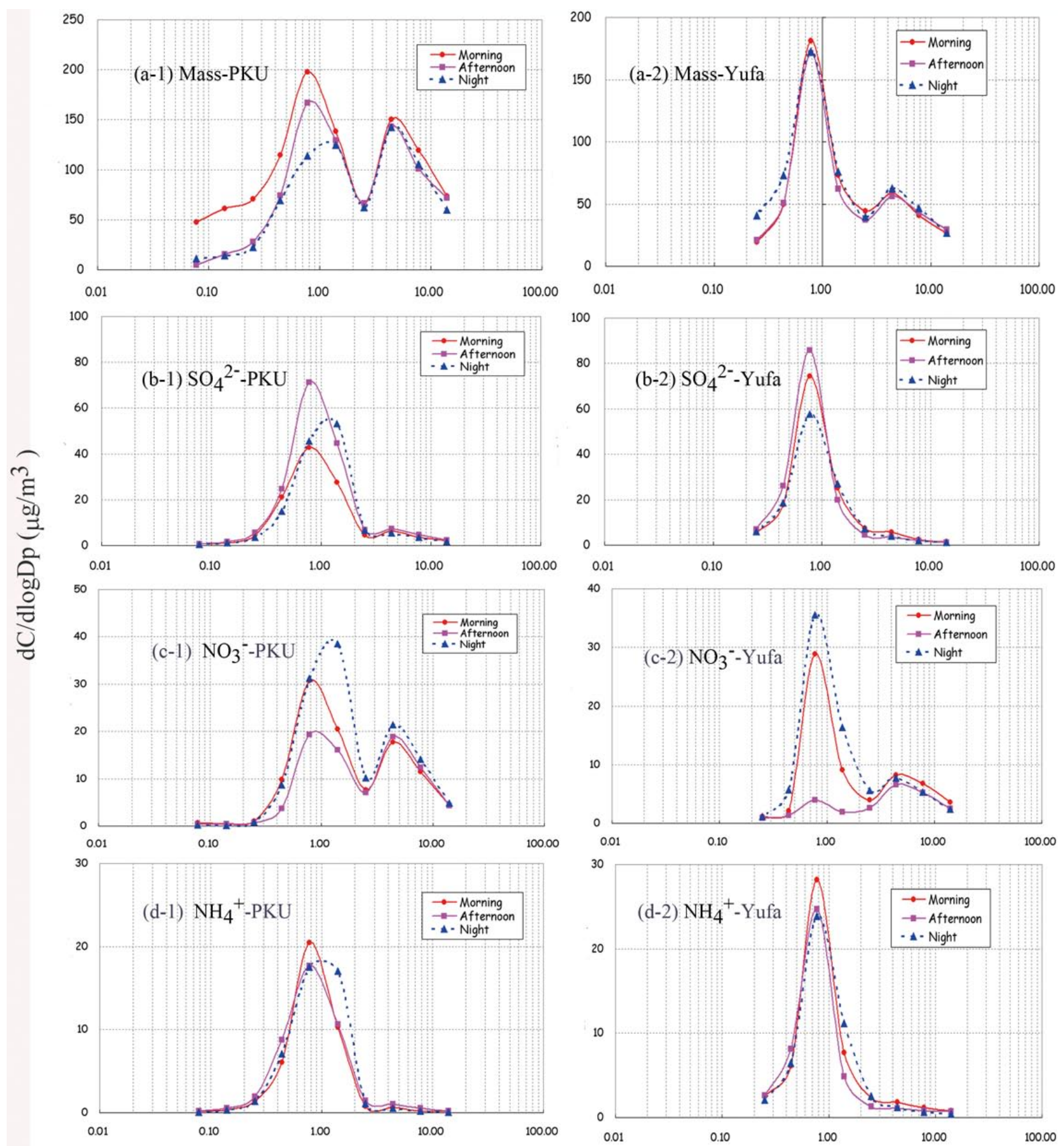

Particle aerodynamic diameter $(\mu \mathrm{m})$

Fig. 4. Measured average size distributions of mass and major secondary ionic compounds for morning, afternoon and night samples. 
was attributed to gaseous $\mathrm{H}_{2} \mathrm{SO}_{4}$ condensation. This result showed the gas-to-particle conversion was also an important formation pathway for sulfate in summer of Beijing.

\subsubsection{Formation of nitrate}

In-cloud uptake of nitric acid and condensation onto preexisting particles are two possible pathways to form fine mode nitrates. In this work, fine mode nitrate and sulfate exhibited a good correlation with $R^{2}=0.78$ at Yufa, indicating their formation pathways may be similar. The PMF results showed that $59 \%$ and $16 \%$ of the nitrate were formed by in-cloud and gas-to-particle condensation process. However, the correlation at PKU was weak with $R^{2}=0.41$, suggesting at PKU the nitrate formation was different from sulfate, so the formation pathway of nitrate at PKU will be discussed in detail below.

The measuring of particle $\mathrm{NH}_{4} \mathrm{NO}_{3}$ has a lot of artifacts due to its semi- volatility, and this has been known for a long time and has been documented in detail in the literature (Chow, 1995). These artifacts are mainly caused by topological reactions, and evaporation of ammonium nitrate. Topological reactions will be important noticeable if the loading of the filters is high, because nitrate can react with sulfuric acid to form nitric acid, which will lose by evaporation. Thus, more nitrate will be lost if the sampling period is long (e.g. $24 \mathrm{~h}$ ). The evaporation of $\mathrm{NH}_{4} \mathrm{NO}_{3}$ could also take place during the sampling, especially when in the afternoon the temperature was high and the humidity is low. Both these aspects could make the filter measurement underestimate the concentrations of nitrate and ammonium. Online instrument with short sampling time can effectively reduce the artifacts, so in this study, particle compositions $\mathrm{SO}_{4}^{2-}, \mathrm{NO}_{3}^{-}$and $\mathrm{NH}_{4}^{+}$ were also measured by the on-line aerosol and gas instrument Wet Denuder-SJAC (Steam Jet Aerosol Collector) system (Slanina, et al., 2001). Wet Denuder-SJAC can also measure gaseous $\mathrm{NH}_{3}$ and $\mathrm{HNO}_{3}$.

Many studies have reported that fine mode nitrate was ammonium nitrate, but the chemistry of coarse mode nitrate in different locations can be diverse, not only $\mathrm{NH}_{4} \mathrm{NO}_{3}$ but also $\mathrm{NaNO}_{3}$ and $\mathrm{Ca}\left(\mathrm{NO}_{3}\right)_{2}$ have been reported (Pakkanen et al., 1996). Basically, the size distribution of nitrate is influenced by the thermodynamic equilibrium of

$$
\mathrm{HNO}_{3}(\mathrm{~g})+\mathrm{NH}_{3}(\mathrm{~g}) \leftrightarrow \mathrm{NH}_{4} \mathrm{NO}_{3}(\mathrm{~s}, \mathrm{aq})
$$

When the $\left[\mathrm{NH}_{3}\right] \times\left[\mathrm{HNO}_{3}\right]$ is larger than the equilibrium constant Ke', formed $\mathrm{NH}_{4} \mathrm{NO}_{3}$ (s, l) can be stable. Otherwise nitrate can exist in coarse mode. The equilibrium constant $\mathrm{Ke}$ for pure $\mathrm{NH}_{4} \mathrm{NO}_{3}$ is determined by temperature, ambient $\mathrm{RH}$ and the concentrations of $\mathrm{HNO}_{3}(\mathrm{~g})$ and $\mathrm{NH}_{3}(\mathrm{~g})$. In this study $\mathrm{Ke}$ is calculated using the method suggested by Michael (1993). The coexistence of $\mathrm{SO}_{4}^{2-}$ in particles considerably reduces Ke. To determine $\mathrm{Ke}$ ' for the $\mathrm{NH}_{4}+/ \mathrm{NO}_{3}^{-} / \mathrm{SO}_{4}^{2-}$ system, the $\mathrm{NH}_{4} \mathrm{NO}_{3}$ ionic strength fraction $\mathrm{Y}$ was calculated

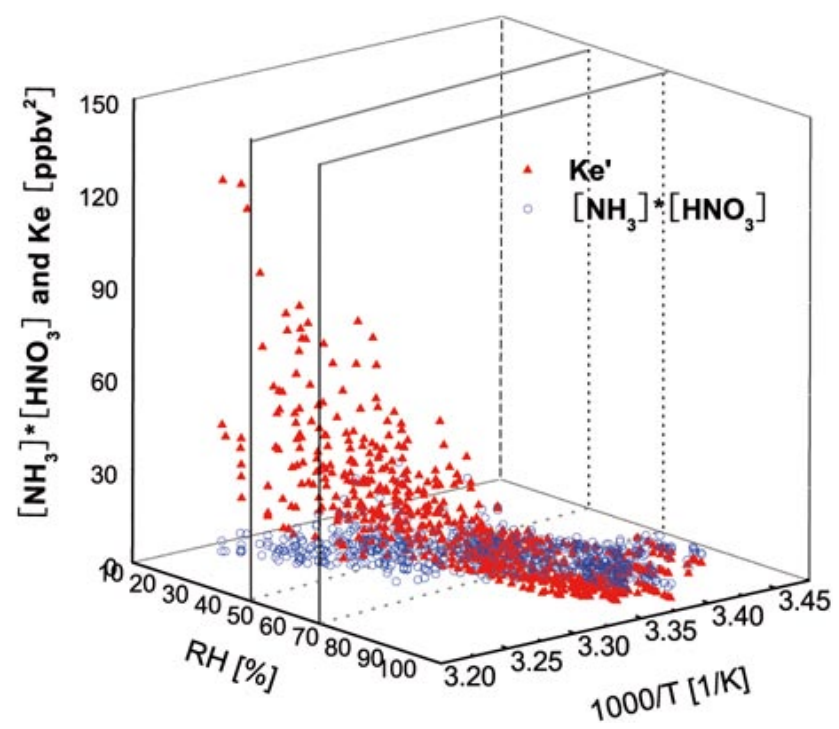

Fig. 5. Equilibrium constant (Ke') and measured $\left[\mathrm{NH}_{3}\right] \times\left[\mathrm{HNO}_{3}\right]$ at PKU during the campaign. Red triangles for Equilibrium constant Ke', blue circles for measured $\left[\mathrm{NH}_{3}\right] \times\left[\mathrm{HNO}_{3}\right]$, rectangles for $\mathrm{RH}=50 \%, 70 \%$.

according to Stelson and Seinfeld (1982). Ke' was then derived by multiplying Ke with Y.

The equilibrium constant (Ke') and the measured $\left[\mathrm{NH}_{3}\right] \times\left[\mathrm{HNO}_{3}\right]$ were calculated by using SJAC data. Figure 5 shows the equilibrium constant (Ke') as calculated and as measured $\left[\mathrm{NH}_{3}\right] \times\left[\mathrm{HNO}_{3}\right]$ at $\mathrm{PKU}$ during the campaign. Both temperature and relative humidity had great impact on the size distribution of nitrate. However, the variation of temperature was small $\left(22.3 \sim 30.1^{\circ} \mathrm{C}\right)$, which means very small change of temperature can lead to large change of Ke'. It's difficult to set a critical point of coarse-to-fine mode shifting by using temperature. Three kinds of cases were classified by RH: (1) when the relative humidity was lower than $50 \%$, the red triangles in Fig. 5 are much higher than corresponding blue circles, and the $\mathrm{Ke}$ ' values were about one order larger than the measured $\left[\mathrm{NH}_{3}\right] \times\left[\mathrm{HNO}_{3}\right]$ products. Under this condition, and $\mathrm{NH}_{4} \mathrm{NO}_{3}$ dissociated and formed coarse mode nitrate by reactions of nitric acid with $\mathrm{CaCO}_{3}, \mathrm{~K}_{2} \mathrm{CO}_{3}$ or $\mathrm{NaCl}$. (2) When the humidity was between $50 \%-70 \%$, the measured products were often in the same order compared to Ke'. $\mathrm{NH}_{4} \mathrm{NO}_{3}$ can partly dissociate, and existed in both fine particles and coarse particles. (3) When the humidity was over $70 \%$, the triangles and circles are close to each other. Sometimes, the measured $\left[\mathrm{NH}_{3}\right] \times\left[\mathrm{HNO}_{3}\right]$ was even higher than Ke'. This may happen after midnight when the humidity was very high. Under this condition, $\mathrm{NH}_{4} \mathrm{NO}_{3}$ is found in fine particles. This classification can be validated by measured size distribution results.

At Yufa the nitrate size distributions agreed with the above classification very well. However, the case at PKU site was quite different. In the afternoon, the RH was usually below 
Table 3. Linear regressions between the cations and nitrate in fine particles in the afternoon samples at PKU, using $y=b x+c$, in which $\mathrm{y}$ represents molar concentration of $\mathrm{Na}^{+}, \mathrm{K}^{+}$or twice $\mathrm{Ca}^{2+}, x$ molar concentration of nitrate, $n=12$.

\begin{tabular}{lllllllll}
\hline $\begin{array}{l}\text { Regress } \\
\text { coefficients }\end{array}$ & \multicolumn{3}{c}{$1-1.8 \mu \mathrm{m}$} & \multicolumn{3}{c}{$0.56-1 \mu \mathrm{m}$} \\
\hline & $\mathrm{Na}^{+}$ & $\mathrm{K}^{+}$ & $2^{*} \mathrm{Ca}^{2+}$ & $\mathrm{K}^{+}+2^{*} \mathrm{Ca}^{2+}$ & $\mathrm{Na}^{+}$ & $\mathrm{K}^{+}$ & $2 * \mathrm{Ca}^{2+}$ & $\mathrm{K}^{+}+2^{*} \mathrm{Ca}^{2+}$ \\
$b$ & 0.17 & 0.37 & 0.9 & 0.99 & 0.17 & 0.42 & 0.23 & 0.6 \\
$c$ & 0.0016 & 0.0009 & -0.0006 & 0.0033 & 0.0012 & 0.001 & 0.0013 & 0.0029 \\
$R^{2}$ & 0.61 & 0.78 & 0.94 & 0.97 & 0.72 & 0.9 & 0.97 & 0.95 \\
\hline
\end{tabular}

$50 \%$, but considerable amounts of fine particle nitrate were measured (Fig. $4 \mathrm{c}-1$ ), so there must be other cations that combined with nitrate in fine particles besides ammonium. Crustal aerosol like $\mathrm{CaCO}_{3}$ can also react with nitric acid to form $\mathrm{Ca}\left(\mathrm{NO}_{3}\right)_{2}$. It was generally assumed that calcium is mainly present in the coarse particles, so these reactions would be only relevant for coarse particles. The calcium in fine particle was seldom investigated in previous studies. However, the results of this study show that $29 \%$ of the water-soluble $\mathrm{Ca}^{2+}$ was in fine particles. Moreover, $\mathrm{K}^{+}$ was abundant in fine particles, so it was possible that fine mode nitrate can exist as the form of $\mathrm{Ca}\left(\mathrm{NO}_{3}\right)_{2}$ or $\mathrm{KNO}_{3}$. The molar ratios of $r^{\prime}$ and $r$ in stage $0.56-1 \mu \mathrm{m}$ and 1-1.8 $\mu \mathrm{m}$ were calculated to show that sufficient $\mathrm{Ca}^{2+}, \mathrm{K}^{+}$and $\mathrm{Na}^{+}$is present:

$r^{\prime}=\frac{\left[\mathrm{Na}^{+}\right]+\left[\mathrm{K}^{+}\right]+2 \times\left[\mathrm{Ca}^{2+}\right]}{\left[\mathrm{NO}_{3}^{-}\right]+\left[\mathrm{Cl}^{-}\right]}$

$r=\frac{\left[\mathrm{K}^{+}\right]+2 \times\left[\mathrm{Ca}^{2+}\right]}{\left[\mathrm{NO}_{3}^{-}\right]}$

The weather conditions of 24th and 25th August were different from those of other days, so the discussion below will not include these two days. The calculation results showed that $r^{\prime}$ ranged from 0.84 to 1.36 , and $r$ ranged from 0.74 to 1.43 , indicating these cations were abundant enough to combine with nitrate. In addition, the correlation between these cations and nitrate in the afternoon samples was investigated (Table 3). $\mathrm{Na}^{+}, \mathrm{K}^{+}$and $\mathrm{Ca}^{2+}$ showed good correlation with nitrate, implying in the afternoon samples at PKU, nitrate was of great possibility to exist as $\mathrm{NaNO}_{3}, \mathrm{KNO}_{3}$ and $\mathrm{Ca}\left(\mathrm{NO}_{3}\right)_{2}$. Moreover, in the stage of $1-1.8 \mu \mathrm{m}, \mathrm{Ca}^{2+}$ was the most abundant in these three cations, and had best correlation with nitrate, so $\mathrm{Ca}\left(\mathrm{NO}_{3}\right)_{2}$ may be dominant in this stage. For the same reason, in the stage of $0.56-1 \mu \mathrm{m}, \mathrm{KNO}_{3}$ may be important, although $\mathrm{NH}_{4} \mathrm{NO}_{3}$ was also probably present in this stage. PMF results also give evidences to confirm this, for both model resolved coarse mode calcium and nitrate contributed to small size stages $(<1.8 \mu \mathrm{m})$. Assuming the resolved coarse mode nitrate was as the form of $\mathrm{Ca}\left(\mathrm{NO}_{3}\right)_{2}$ by the reaction of $\mathrm{HNO}_{3}$ with crustal particles. Thus, the model results showed that $13 \%, 30 \%$ and $7 \%$ of nitrate in $\mathrm{PM}_{1.8}$ was as the form of $\mathrm{Ca}\left(\mathrm{NO}_{3}\right)_{2}$ at PKU site in the morning, afternoon and night, respectively. The corresponding fractions at Yufa were 5\%,12\% and 3\%. As mentioned above, theses $\mathrm{Ca}\left(\mathrm{NO}_{3}\right)_{2}$ may the one reason for the peak "shift" at PKU. However, this was not an important reason, because an average of only $14 \%$ of the nitrate was formed as $\mathrm{Ca}\left(\mathrm{NO}_{3}\right)_{2}$ in fine particles, and the fraction was the lowest at night when the fine mode peak "shifted" to lager size.

The afternoon samples of 24th and 25th August were special cases. The amounts of the three cations were too low to act as counter-ions for nitrate, the average temperatures during these two sampling periods were below 30 degree and average $\mathrm{RH}$ was higher than $60 \%$, indicating that ammonium nitrate was possible dominant form of fine mode nitrate.

In conclusion the reaction of $\mathrm{HNO}_{3}$ with crustal particles was not only important in coarse particles but also in fine particles in the summer of Beijing especially in urban aera.

\subsubsection{Formation of oxalate}

Oxalate is typically the most abundant dicarboxylic acid in atmospheric aerosols, and has been found in particle composition in various environments (Narukawa et al., 2003). Oxalate can come from primary emission of vehicle exhausts (Kawamura and Kaplan, 1987), biomass burning (Narukawa et al., 1997) and biogenic activity (Kawamura, 1996). Biomass burning can release oxalic acid, and oxalate correlates well with $\mathrm{K}^{+}$in these particles (Narukawa et al., 1999). However, in this study, oxalate had a poor correlation with $\mathrm{K}^{+}\left(R^{2}=0.43\right.$, PKU; $R^{2}=0.07$, Yufa), indicating biomass burning was not a major source of oxalate. Plant leaves do not emit oxalic acid directly, but fatty acids released by plant may be broken down to form oxalic (Kawamura et al., 1996). Biogenic activities in the soil and the roots of plants can also generate oxalic acid (Jones, 1998). So far the formation of oxalate by biological aerosols is not well understood yet. Above all, primary emission was not the main source of oxalate in the summer of Beijing.

Another source of oxalate is from secondary transformation. The condensation mode oxalate is mainly from the photochemical process in the gas phase to form gaseous oxalic 
acid, followed by its condensation onto existing particles. However, it is impossible for condensation mode oxalate to directly grow up into droplet mode in Beijing, because only at very high $\mathrm{RH}$ of $97 \%$ (at $25^{\circ} \mathrm{C}$ ), the condensation mode of pure oxalic acid or the mixture of oxalic acid, sulfate and nitrate can grow up into droplet mode by hygroscopic growth (Peng et al., 2001). Thus, it is possible that the condensation mode oxalate-containing particles were activated and became the droplet mode particles after in-cloud or aerosol droplet process in Beijing.

Generally, similar size distributions indicate similar formation processes. The size distributions of oxalate were almost of the same as those of sulfate, and oxalate and sulfate were highly correlated with correlation coefficients of 0.89 and 0.90 at PKU and Yufa respectively, strongly suggesting that oxalate and sulfate originated from similar atmospheric processes. Many studies have reported the good correlations between sulfate and oxalate (Huang et al., 2006). From the PMF results, $67 \%$ of oxalate at PKU and $55 \%$ at Yufa were formed by in-cloud or aerosol droplet process. Correspondingly, $19 \%$ and $25 \%$ were due to gas-particle condensation.

\subsection{Assessment of local and regional particulate pollution}

With the rapid urbanization, the presence of regional pollution in cities has been recognized. This pollution considers a background whose concentrations and variations are within regional scale, and can limit efforts to reduce air pollution in cities. A work by Jia et al. (2008) suggested that the regional pollution is mainly due to secondary formation and the horizontal homogeneity of the meteorological conditions. However, this regional concentration is difficult to quantify, even with transport models (Han et al., 2005). As for the importance of secondary particle pollution in Beijing summer, it is necessary to quantitatively assess the local and regional particulate pollution in order to better characterize the regional secondary particle pollution in summer of Beijing.

To estimate regional contribution, first the regional character should be recognized for the components (e.g. mass or chemical compositions), and then diverse assumptions are made to do the estimations. Jia et al. (2008) described a novel technique for quantifying regional aerosol from a series of fast-response measurements of total aerosol based on the assumption of the "sawtooth cycles". However, this method needs large quantities of long-term and high resolution data. This study offers a simple method to roughly estimate the regional contribution by using short time and low time resolution data from multi-sites. Several assumptions were made in this method: (1) The particle concentrations of urban site was only from regional and local contribution. The regional contribution included regional background concentration and regional transport, which in this study contributed very little, and can be considered as a very small constant due to the stagnant weather condition. (2) The particle concentrations at the regional site Yufa can be considered as homogeneous regional background concentration plus local contribution at Yufa which can also be regarded as a small constant due to very few local effects. (3) The particle pollution at two sites had similar variations, and the contribution, which the urban area gives to the regional area, is linear. Under these assumptions, the urban particle concentration $C_{\text {urban }}$ can be present as:

$C_{\text {urban }}=C_{\mathrm{PKU}}=R+L=\left(R_{b}+R_{t}\right)+L=R_{b}+L+c_{0}$

in which, $R, R_{b}$ and $R_{t}$ are regional, regional background and regional transport contribution, and $\mathrm{L}$ is local contribution. Due to assumption (1), $R_{t}$ can be assumed as a constant $c_{0}$. According to assumption (2) and (3), $R_{b}$ equals to $C_{\text {Yufa }}$ plus local contribution $c_{0}^{\prime}$, and $R$ can be expressed as $b \cdot C_{\mathrm{PKU}}$, in which $b$ is the fraction of regional contribution. Thus the Eq. (4) can be transformed to Eq. (5):

$b \cdot C_{\mathrm{PKU}}=C_{\mathrm{Yufa}}+c$

in which $c$ is sum of $c_{0}$ and $c_{0}^{\prime}$.

In this case, linear regression can be used to get the regional contribution fraction $b$.

In this study, the particle concentrations at two sites showed similar trends and were strongly correlated ( $R^{2}=0.86$ for $\mathrm{PM}_{1.8}, R^{2}=0.83$ for $\mathrm{PM}_{10}, n=28$ ), this clearly points to the regional character of particle concentrations. By the method above, an average regional contribution of $69 \%$ was estimated for $\mathrm{PM}_{10}$ and $87 \%$ for $\mathrm{PM}_{1.8}$. This result was consistent with the study of Jia et al. (2008), in which $70 \%$ of the urban $\mathrm{PM}_{10}$ concentration was estimated from regional contribution during southerly flow.

The uncertainty of this method was decided mainly by two aspects: the variations of local contribution at Yufa and transport contribution at PKU, which was reflected by offset $c$. The calculations showed a very small positive $c\left(0.92 \mu \mathrm{g} / \mathrm{m}^{3}\right)$ which contributed only $5 \pm 4 \%$ to the urban particle concentration. The positive $c$ value also indicates that at least regional transport did contribute to urban particle pollution, although the contribution was less than $5 \%$.

The correlation between PKU and Yufa regarding sulfate in $\mathrm{PM}_{1.8}$ was good $\left(R^{2}=0.81, n=28\right)$ during stagnant days, suggesting the regional sulfate pollution. The same variation of SORs at two sites also indicated the regional production of sulfate. Using the same estimating method, about $90 \%$ of the sulfate in $\mathrm{PM}_{1.8}$ at $\mathrm{PKU}$ is regional. Oxalate and ammonium were also formed regionally, with average regional contributions of $95 \%$ and $87 \%$ respectively.

As mentioned above, nitrates at two sites had different formation pathways, suggesting the formations of nitrate at two sites depended more on local conditions. Moreover, the nitrate in $\mathrm{PM}_{1.8}$ showed weak correlation between PKU and Yufa, with $R^{2}=0.34$. All these differences indicate that nitrate was formed locally other than regionally.

Because the regional particle pollution is very complicated and the assumptions of this method have many uncertainties, 
this method can only give very rough estimation. However, this method gives an approach to estimate regional contribution with only short time and low time resolution data.

\section{Conclusion}

In summer of Beijing, the particle concentrations were both high at urban site and rural site. The fine particles have become the major component of $\mathrm{PM}_{10}$, and secondary pollution was more and more important these years. Three modes were resolved at Yufa by PMF model, representing three major sources of particles. However, one more droplet mode with bigger size was resolved, which was considered probably from regional transport, but more evidences were needed to prove this. Condensation mode should also be taken into account for its contribution of more than $1 / 4$ to total mass. The PMF results can be used to quantify the contribution of each formation pathway. As a result, $80 \%$ of the sulfate at PKU and $70 \%$ at Yufa were due to in-cloud process or aerosol droplet process, and correspondingly $14 \%$ and $22 \%$ were due to gas condensation process. Oxalate had similar formation pathway as sulfate, with the contributions of $67 \%$ at PKU and $55 \%$ at Yufa due to in-cloud or aerosol droplet process. Nitrate size distributions were classified as three categories by $\mathrm{RH}$ due to the thermodynamic instability of $\mathrm{NH}_{4} \mathrm{NO}_{3}$. The nitrate in fine particles in the afternoon at PKU was probably $\mathrm{Ca}\left(\mathrm{NO}_{3}\right)_{2}$ in stage $1-1.8 \mu \mathrm{m}$ and $\mathrm{KNO}_{3}$ in the stage of 0.56 $1 \mu \mathrm{m}$, indicating the reaction of $\mathrm{HNO}_{3}$ with soil particles was not only important in coarse particles, but also in fine particles. Linear regression was used to roughly estimate the regional particle contribution. As a result, $69 \%$ of $\mathrm{PM}_{10}$ and $87 \%$ of $\mathrm{PM}_{1.8}$ at PKU were regional contributions. Sulfate, ammonium and oxalate were formed regionally, with the regional contributions of $90 \%, 87 \%$ and $95 \%$ to $\mathrm{PM}_{1.8}$ at PKU. Nitrate formation was local dominant.

Acknowledgements. This work as part of CAREBEIJING 2006 (Campaign of Atmospheric Researches in Beijing and surrounding areas in 2006) were supported by Beijing Council of Science and Technology (HB200504-2, HB200504-6), The National Natural Science Foundation of China (20637020), the National Key Technologies R \& D Program in the Eleventh Five-year Plan Period from the Ministry of Science and Technology (2006BAI19B06). and EUCAARI(European Integrated project on Aerosol Cloud Climate and Air Quality interactions) No 036833-2. The authors would like to thank Wenting Zhang, Danjue Chen, Yunpeng Li, Jianwei Gu for their help during the campaign. Thanks to James J. Schauer, Yu Song and Roeland Jansen for their suggestions and editing advice.

Edited by: V.-M. Kerminen

\section{References}

Anlauf, K., Li, S. M., Leaitch, R., Brook, J., Hayden, K., ToomSauntry, D., and Wiebe, A.: Ionic composition and size characteristics of particles in the lower Fraser Vellay: Pacific 2001 field study, Atmos. Environ., 40, 2662-2675, 2006.

Chen, Y., Zhao, C., Zhang, Q., Deng, Z., Huang, M., and Ma, X.: Aircraft study of Mountain Chimney Effect of Beijing, China, J. Geophys. Res., 114, D08306, doi:10.1029/2008JD010610, 2009.

Chow, J.: Critical review of measurement methods to determine compliance with ambient air quality standards for suspended particulates, J. Air. Waste Manage., 45, 320-382, 1995.

Frenich, A. G., Galera, M. M., Vidal, J. L. M., Massart, D. L., Torres-Lapasio, J. R., De Braekeleer, K., Wang, J. H., and Hopke P. K.: Resolution of multicomponent peaks by orthogonal projection approach, positive matrix factorization and alternating least squares, Anal. Chem. Acta, 411, 145-155, 2000.

Han, L. H., Zhuang, G. S., Yele, S., and Wang, Z. F.: Local and non-local sources of airborne particulate pollution at Beijing, Sci. China. Ser B, 48(3), 253-264, 2005.

He, K. B., Yang, F. M., Ma, Y. L., Zhang, Q., Yao, X. H., Chan, C. K., Cadle, S., Chan, T., and Mulawa, P.: The characteristics of PM2.5 in Beijing, China, Atmos. Environ., 35(29), 4959-4970, 2001.

Hu, M., Zhao, Y. L., He, L. Y., Huang, X. F., Tang, X. Y., Yao, X. H., and Chan, C. K.: Mass Size Distribution of Beijing Particulate Matters and Its Inorganic Water-Soluble Ions in Winter and Summer, Environ. Sci., 26(4), 1-6, 2005 a.

$\mathrm{Hu}$, M., Zhang, J., and Wu, Z. J.: Chemical compositions of precipitation and scavenging of particles in Beijing, Sci. China. Ser B, 48(3), 265-272, $2005 b$.

Huang, X. F., Yu, J. Z., He, L. Y., and Yuan, Z. B.: Watersoluble organic carbon and oxalate in aerosols at a coastal urban site in China: Size distribution characteristics, sources, and formation mechanisms, J. Geophys. Res., 111, D22212, doi:10.1029/2006JD007408, 2006.

Jia, Y. T, Rahn, K. A., He, K. B., Wen, T. X., and Wang, Y. S.: A novel technique for quantifying the regional component of urban aerosol solely from its sawtooth cycles, J. Geophys. Res., 113, D21309, doi:10.1029/2008JD010389, 2008.

Jones, D. L.: Organic acids in the rhizosphere - a critical review, Plant Soil, 205, 25-44, 1998.

Kawamura, K. and Kaplan, I. R.: Motor exhaust emission as a primary source for dicarboxylic acids in Los Angeles ambient air, Environ. Sci. Technol., 21, 105-110, 1987.

Kawamura, K., Kasukabe, H., and Barrie, L. A.: Source and reaction pathways of dicarboxylic acids, ketoacids and dicarbonyls in Arctic aerosols: one year of observations, Atmos. Environ., 30, 1709-1722, 1996.

Kim, E., Hopke, P. K., Larson, T. V., and Covert, D. S.: Analysis of ambient particle size distributions using UNMIX and positive matrix factorization, Environ. Sci. Technol., 38, 202-209, 2004.

Kleeman, M. J., Schauer, J. J., and Cass, G. R.: Size and composition distribution of fine particulate matter emitted from wood burning, meat charbroiling and cigarettes, Environ. Sci. Technol., 33, 3516-3523, 1999.

Liu, S., Hu, M., Slanina J., He, L. Y., Niu, Y. W., Bruegemann, E., Gnauk, T., and Herrmann, H.: Size distribution and source analysis of ionic compositions of aerosols in polluted periods at Xinken in Pearl River Delta (PRD) of China, Atmos. Environ., 
42(25), 6284-6295, 2008.

Michael, M.: The dissociation constant of ammonium nitrate and its dependence on temperature, relative humidity and particle size, Atmos. Environ., 27A, 261-270, 1993.

Narukawa, M., Kawamura, K., Anlauf, K. G., and Barrie, L. A.: Fine and coarse modes of dicarboxylic acids in the Arctic aerosols collected during the Polar Sunrise Experiment 1997, J. Geophys. Res., 108(D18), 4575, doi:10.1029/203JD003646, 2003.

Narukawa, M., Kawamura, K., Takeuchi, N., and Nakajima, T.: Distribution of dicarboxylic acids and carbon isopotic compositions in aerosols from 1997 Indonesian forest fires, Geophys. Res. Lett. 26, 3101-3104, 1999.

NBSC, National Bureau of Statistics of China: Bulletin of Statistics for Beijing, Part Two: Population, People life and social security, available online at: http://www.stats.gov.cn/tjsj/ndsj/2008/ indexeh.htm, 2009a.

NBSC, National Bureau of Statistics of China: Bulletin of Statistics for Beijing, Part Three: Resource, Energy and Environment, available online at: http://www.stats.gov.cn/tjsj/ndsj/2008/ indexeh.htm, 2009b.

Pakkanen, T. A., Kerminen, V. M., Hillamo, R. E., Makinen, M., Makela, T., and Virkkula, A.: Distribution of nitrate over seasalt and soil derived particles implications from a field study, J. Atmos. Chem., 24, 189-205, 1996.

Peng, C. and Chan, C. K.: The water cycles of water soluble organic salts of atmospheric importance, Atmos. Environ., 35, 11831192, 2001.

Seinfeld, J. H. and Pandis, S. N.: Atmospheric chemistry and physics-from air pollution to climate change, John Wiley \& Sons, Inc., New York, USA, 23-24,, 1998.

Shao, M., Tang, X. Y., Zhang, Y. H., and Li, W. J.: City Clusters in China: Air and Surface Water Pollution, Front Ecol. Environ., 4(7), 353-361, 2006.

Slanina, J., ten Brink, H. M., Otjes, R. P., Even, A., Jongejan, P., Khlystov, A., Waijers-Ijpelaan, A., Hu, M., and Lu, Y.: The continuous analysis of nitrate and ammonium in aerosols by the steam jet aerosol collector (SJAC): extension and validation of the methodology, Atmos. Environ., 35, 2319-2330, 2001.

Song, Y., Zhang, Y. H., Xie, S. D., Zeng, L. M., Zheng, M., Salmon, L. G., Shao, M., and Slanina, S.: Source apportionment of PM2.5 in Beijing by positive matrix factorization, Atmos. Environ., 40, 1526-1537, 2006.
Stelson, A. W. and Seinfeld, J. H.: Thermodynamic prediction of the water activity, $\mathrm{NH}_{4} \mathrm{NO}_{3}$ dissociation-constant, density and refractive index for the $\mathrm{NH}_{4} \mathrm{NO}_{3}-\left(\mathrm{NH}_{4}\right)_{2} \mathrm{SO}_{4}-\mathrm{H}_{2} \mathrm{O}$ system at 25-degrees-C, Atmos. Environ., 16(10), 2507-2514, 1982.

Sun, Y. L., Zhuang, G. S., Tang, A. H., Wang, Y., and An, Z. S.: Chemical characteristics of $\mathrm{PM}_{2.5}$ and $\mathrm{PM}_{10}$ in haze-fog episodes in Beijing, Environ. Sci. Technol., 40(10), 3148-3155, 2006.

van Pinxteren, D., Brueggemann, E., Gnauk, T., Iinuma, Y., Mueller, K., Nowak, A., Achtert, P., Wiedensohler, A., and Herrmann, H.: Size- and time-resolved chemical particle characterization during CAREBeijing-2006: Different pollution regimes and diurnal profiles, J. Geophys. Res., 114, D00G09, doi:10.1029/2008JD010890,, 2009.

Wang, L. T., Hao, J. M., He, K. B., Wang, S. X., Li, J. H. Zhang, Q., Streets, D. G., Fu, J. S., Jang, C. J., Takekawa, H., and Chatani, S.: A modeling study of coarse particulate matter pollution in Beijing: Regional source contributions and control implications for the 2008 summer Olympics, J. Air Waste Manage, 58(8), 1057-1069, 2008.

Yang, F., He, K., Ye, B., Chen, X., Cha, L., Cadle, S. H., Chan, T., and Mulawa, P. A.: One-year record of organic and elemental carbon in fine particles in downtown Beijing and Shanghai, Atmos. Chem. Phys., 5, 1449-1457, 2005, http://www.atmos-chem-phys.net/5/1449/2005/.

Yao, X. H., Chan, C. K., Fang, M., Cadle, Chan, S. T., Mulawa, P., He, K. B. and Ye, B. M.: The water-soluble ionic composition of PM2.5 in Shanghai and Beijing, China, Atmos. Environ, 36(26), 4223-4234, 2002.

Yao, X. H., Lau, A. P. S., Fang, M., Chan, C. K., and Hu, M.: Size distributions and formation of ionic species in atmospheric particulate pollutants in Beijing, China: 1 - inorganic ions, Atmos. Environ., 37(21), 2991-3000, 2003.

Zhuang, H., Chan, C. K., Fang, M., and Wexler, A. S.: Formation of nitrate and non-sea-salt sulfate on coarse particles, Atmos. Environ., 33, 4223-4233, 1999. 